\title{
Anatomical and Ultrastructure Differences Between Some Species of the Genus Elsholtzia Willd. of Flora of Ukraine
}

\author{
Liudmyla Zotsenko ${ }^{1, *}$, Nataliia Nuzhyna ${ }^{2}$, Viktoria Kyslychenko ${ }^{3}$, Oksana Futorna ${ }^{2}$
}

\section{Liudmyla Zotsenko ${ }^{1, *}$, Nataliia Nuzhyna ${ }^{2}$, Viktoria Kyslychenko ${ }^{3}$, Oksana Futorna ${ }^{2}$}

'State Laboratory of Quality Control of Medicines, State Institution, Institute of Pharmacology and Toxicology National Academy of Medical Sciences of Ukraine Kyiv, UKRAINE.

${ }^{2}$ NSC "Institute of Biology and Medicine" Taras Shevchenko National University of Kyiv, Kyiv, UKRAINE.

${ }^{3}$ National University of Pharmacy,

Department of Chemistry of Natural

Compounds, Kharkiv, UKRAINE.

\section{Correspondence}

\section{Liudmyla Zotsenko}

Junior researcher, State Laboratory of Quality Control of Drugs, State Institution, Institute of Pharmacology and Toxicology National Academy of Medical Sciences of Ukraine, AntonaTsedika str., 03057, Kyiv, UKRAINE.

Phone no: +380932574587

E-mail: lebenspiel777@gmail.com

History

- Submission Date: 18-03-2021;

- Review completed: 07-05-2021;

- Accepted Date: 18-05-2021.

DOI : 10.5530/pj.2021.13.126

Article Available online http://www.phcogj.com/v13/i4

\section{Copyright}

(C) 2021 Phcogj.Com. This is an openaccess article distributed under the term of the Creative Commons Attribution 4.0 International license.

\begin{abstract}
Introduction: Elsholtzia species are very popular in Chinese, Tibetan and Vietnamese folk medicine to treat several diseases. Despite the wide range of biological activity and the study of the chemical composition of individual species, the microscopic characteristics of plants of this genus are insufficiently studied. In the article the anatomical structure of two species Elsholtzia Willd. of flora of Ukraine is represented. The sources of literature provide only a morphological description of Elsholtzia stauntonii and Elsholtzia ciliate. We analyzed crosssections and ultrastructure of leaf blade, petiole, petal and stem, determined their anatomical features, and investigated the ultrastructure of seeds. We have compared the obtained data between this two species of this genus that grow on the territory of Ukraine under similar conditions. Methods: Microscopic analysis was carried out by the well-known methods using the microscope XSP-146TR and ImageJ program. Anatomical structure of Elsholtzia stauntonii Benth. and Elsholtzia ciliate Thun. are studied and main diagnostic features are highlighted. The ultrastructure of the surface of the epidermal tissue of leaves, stems and seeds were studied additionally, using scanning microscopy methods. Results: The diagnostic microscopic distinguishing features of $E$. ciliate raw material from $E$. stauntonii are: the presence of small glandular trichomes, singly placed on the veins and the presence of long non glandular trichomes on the central vein of abaxial side. Non glandular trichomes of E. ciliate are three times longer compared to another investigated species. The presence of numerous trichomes and massive clusters of stem sclerenchyma E. stauntonii can be considered additional taxonomic criteria for comparing the studied species. Conclusion: The practical significance of our research will use to develop of quality control methods for medicinal herbal raw material - "Herba Elsholtziae Stauntonii», "Herba Elsholtziae ciliate».

Key words: Elsholtzia stauntonii, Elsholtzia ciliate, Stem, Petiole, Petal, Leaf anatomy.
\end{abstract}

\section{INTRODUCTION}

The tribe Elsholtzieae represents a small group within the subfamily Nepetoideae (Lamiaceae). Elsholtzieae consists of seven genera (Collinsonia L., Elsholtzia Willd., Keiskea Miq., Mosla Benth., Ombrocharis Hand.-Mazz, Perilla L. and Perillula Maxim.) and over 70 species containing many medicinally important herbs. The big part - 40 species, belongs to Elsholtzia Willd. genus '. They have been widely distributed and applied in East Asia, Africa, North America, and European countries for centuries, but mainly distributed in southeast and south Asia. Elsholtzia is an economically important plant group. In India and China Elsholtzia species are used in traditional and officinal medicines for the treatment of colds, headaches, pharyngitis, fever, diarrhea, digestion disorder, rheumatic arthritis, nephritises, and nyctalopia ${ }^{2}$. Also, in Asia Elsholtzia plants are used for herbal tea, food, spices, beverages, perfumeries, cosmetics, aromatherapies, and the source of honey manufacture ${ }^{3}$.

The flora of Ukraine numbers only one species that grows as wild plant (Elsholtzia ciliate), and two more species are cultivated (Elsholtzia stauntonii and Elsholtzia densa) ${ }^{4}$.
Elsholtzia is by far the most morphologically diverse genus in the tribe, especially in terms of habit (herbs, subshrubs or shrubs), verticillasters in continuous or interrupted spikes (cylindric or secund, often compact or panicles), shape of the bract (lanceolate, subulate or linear), shape of the calyx (campanulate or cylindric), corolla color (white, yellowish or purplish) and shape of the nutlet (ovate to oblong) 1,5 .

Despite the fact that plants of the genus Elsholtzia Willd. are very different by morphological features, they have a similar range of biologically active substances ${ }^{6,7}$.

According to the literature Elsholtzia plants have a wide range of biological effects: antibacterial, antifungal, antispasmodic, antipyretic, antiinflammatory, analgesic, diuretic and carminative properties. Chinese Vietnamese Balm essential oils are also used in cancer treatment ${ }^{8,9}$. Therefore the genus Elsholtzia recently attracts attention of many researchers.

The aim of this work was to establish the anatomical differences between of two species of the genus Elsholtzia Willd. of flora of Ukraine.

Cite this article: Zotsenko L, Nuzhyna N, Kyslychenko V, Futorna O. Anatomical and Ultrastructure Differences Between Some Species of the Genus Elsholtzia Willd. of Flora of Ukraine. Pharmacogn J. 2021;13(4): 977-987. 


\section{MATERIALS AND METHODS}

As objects of study are selected Elsholtzia stauntonii Benth. (Mint Bush) - perennial plant, and Elsholtzia Patrinii (Lepech.) Garcke or Elsholtzia ciliate Thun. or Elsholtzia cristata Willd., (Chinese Vietnamese Balm) - an annual plant ${ }^{10,11}$

The raw material was gathered in phenophase of the mass flowering on experimental plots of Kyiv O.V. Fomin Botanical Garden and in wild form in the suburbs of Kyiv.

For anatomical studies was taken the middle of the leaf blade, stem, petiole and the middle of the petals of E. stauntonii, E. cliatae. The samples were fixed with Chamberlain's solution (FAA) ${ }^{12}$. The material was poured over with gelatin using standard procedure ${ }^{13}$ and via freezing microtome transverse sections 10-15 microns thick were produced. The sections were stained with safranine or phloroglucinol. Also leaf maceration was carried to study the structures of the epidermis of adaxial and abaxial leaf surfaces ${ }^{16}$. Zaharevich and Baranova methods ${ }^{14,15}$ were used in the description of leaf epidermis plate. Microscopic measurements were performed using eyepiece micrometer on the microscope XSP-146TR and ImageJ program. Statistical analysis of the data was performed using Statistica 8, the reliability of the results was determined by Student's t-test. Photos were taken with a digital camera Canon Power Shot A630.

The ultrastructure of the surface of the epidermal tissue of leaves, stems and petals were further studied using scanning microscopy. Herbarium material was used for the study. Undamaged objects were selected, fixed on a brass table and sprayed with a thin layer of gold and platinum in a vacuum unit. Ultrasculpture of the surface of the autonomic organs was studied using SEM JSM-6060 LA. Descriptions of the surface of leaves and stems were performed using terminology generalized in the works of W. Bathlott, etc .; C. Chakrabarty, P. Mukherjee, S. Zakharevich with certain modifications.

Seeds were described using common terminology. Of the external traits of seeds, the most important are the shape, size, nature of the surface of the test, the location of the scar, the presence of specific structures that promote the spread (Esau, 1977). According to Barthlott (1981, 1984) there are primary and secondary sculpture tests. The primary structure is determined by:

1) the general outlines of cells in the paradermal plane (isodiametric or elongated);

2) the shape of the outer periclinal wall (convex, concave, flat);

3) the shape of the anticline walls (straight, tortuous, thickened, not thickened);

4) outlines visible on the surface of cell boundaries.

The secondary structure is determined mainly by the morphological features of the cuticle (Barthlott, 1981, Goncharova, 2006). Following the common terminology in botany (Artyushenko 1990, Stern, 1992) in cells of elongated shape anticline walls. The most distant from the center of the cell are distal, at the same time close to the center of the cell and perpendicular to the distal are proximal.

\section{RESULTS AND DISCUSSION}

The leaves of studied species of Elsholtzia are dorzoventral, hypostomatic. Epidermal adaxial surface of both species has winding contours, projection area of epidermal cells is flattened (Figure 1, A, B). Epidermal cells on abaxial side are small-winding with flattened projection (Figure 1, C, D). On the abaxial surface of E. stauntonii and E. ciliate stomata are mostly of diacytic type, sometimes anizocytic type (see Figure 1, C, D).
The surface of the leaves is covered with trichomes: on the adaxial leaf surface of both species observed unicellular non-glundular trichomes (thorn-shaped) (Figure $1 \mathrm{E}, \mathrm{F}$ ) and multicellular non-glundular trichomes. On the abaxial surface of the both species simple unicellular trichomes and ether-oil glands with unicellular stalk are placed on ribs (Figure $1 \mathrm{E}, 3 \mathrm{D}$ ). In addition, E. ciliate is characterized by small glandular trichomes on both sides, that are singly plased on the ribs. Such trichomes have unicellular head and unicellular stalk (Figure 1 F). E. stauntonii has only a small number of such glandular trichomes only on the adaxial surface. There are non-glundular trichomes on the abaxial side of the central rib of $E$. ciliate. The studied species were not significantly different by the number of trichomes (Table. 1).

The leaves of both species are covered with single-layer epidermis with cuticle. Adaxial epidermis is almost three times thicker than the abaxial one (Table. 1). Large ether-oil glands are located in crypts formed by abaxial epidermis. The leaf of both species has two layers of palisade mesophyll. Spongy mesophyll is almost twice thinner than palisade. Conducting system of leaves is moderately developed.

\section{Table 1: Morphometric parameters.}

\section{E. stauntonii E. ciliate}

\section{Adaxial side of the leaf}

Area of adaxial epidermal cells, $\mathrm{mkm}^{2}$

$810 \pm 181^{*} \quad 538 \pm 134$

Amount of simple multicellular trichomes $\mathrm{N} / \mathrm{mm}^{2} \quad 2,7 \pm 1,1$

$2,2 \pm 0,8$

Trichomes small number of glandular on veins,

$\mathrm{pc} / \mathrm{mm}^{2}$

Amount of simple unicellular trichomes, $\mathrm{N} / \mathrm{mm}^{2} 48 \pm 12$

$3,9 \pm 0,8$

Abaxial side of the leaf

Area of abaxial epidermal cells, $\mathrm{mkm}^{2}$

$39 \pm 8$

Stomatal length, $\mathrm{mkm}$

Stomatal width, $\mathrm{mkm}$

$351 \pm 71$

$297 \pm 68$

$18 \pm 1^{*} \quad 15 \pm 1$

$14 \pm 1^{*} \quad 12 \pm 1$

$\begin{array}{lll} & 121 \pm 14^{*} & 149 \pm 7\end{array}$

Amount non glandular trichomes on cones, $\mathrm{N} / \mathrm{mm}^{2}$ 9,1 $\pm 1,7^{*} \quad 12,4 \pm 1,1$

Amount great glandular trichomes $\mathrm{N} / \mathrm{mm}^{2} \quad 11,1 \pm 1,8 \quad 11,9 \pm 1,7$

Cross-section of leaf

Thickness of the adaxial epidermis, mkm

$19,5 \pm 2,9^{*} \quad 27 \pm 5$

Thickness outer cells wall of adaxial epidermal

cells, $\mathrm{mkm}$

Thickness of palisade parenchyma, mkm

$2,5 \pm 1,7$

$3,5 \pm 0,8$

Thickness of spongy parenchyma, mkm

$92,3 \pm 2,9^{*} \quad 82,6 \pm 6,9$

Thickness of abaxial epidermis, mkm

$57,8 \pm 3,8^{*} \quad 36,8 \pm 10,4$

$6,5 \pm 1,9^{*} \quad 11,6 \pm 2,2$

Thickness outer cells wall of abaxial epidermal

cells, mkm

$2,2 \pm 1,9^{*} \quad 0,7 \pm 0,3$

Thickness of the leaf

$186,3 \pm 6,3^{*}$

$151,5 \pm 14,1$

Stem

Thickness of the epidermis, mkm

$13 \pm 4^{*} \quad 20 \pm 3$

Thickness outer cells wall of epidermal cells, mkm $1,5 \pm 0,8^{*} \quad 4 \pm 0,3$

Petiole

Thickness of the epidermis adaxial, mkm
Thickness of outer cells wall of adaxial epidermal

Thickness
cells, $\mathrm{mkm}$

Height multicellular trichomes on adaxial ep., mkm

Thickness of the abaxial epidermis, mkm

$14 \pm 2^{*}$

$20 \pm 2$

Thickness of outer cell wall of abaxial epidermal cells, $\mathrm{mkm}$

$3,5 \pm 1,1^{*} \quad 6 \pm 1$

Height multicellular trichomes on abaxial ep., $\mathrm{mkm}$

Petiole length, $\mathrm{mkm}$

$44 \pm 8^{*}$

$174 \pm 43$

$13 \pm 2^{*} \quad 21 \pm 4$

Petal

Trichomes height, mkm

$1,8 \pm 0,3^{*}$

$3,8 \pm 0,9$

Thickness of the petals, mkm

* $-\mathrm{P}<0,05$ - compared to E.ciliate. 


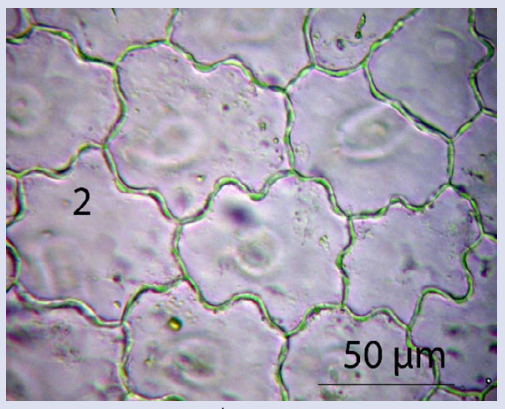

A

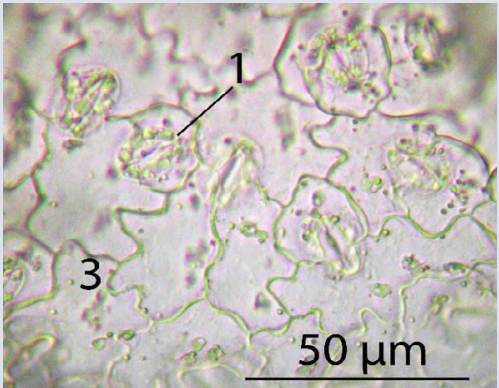

$\mathrm{C}$

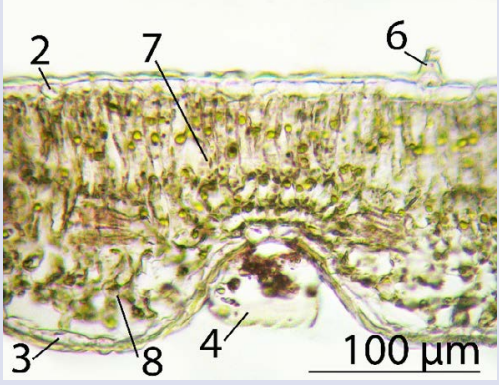

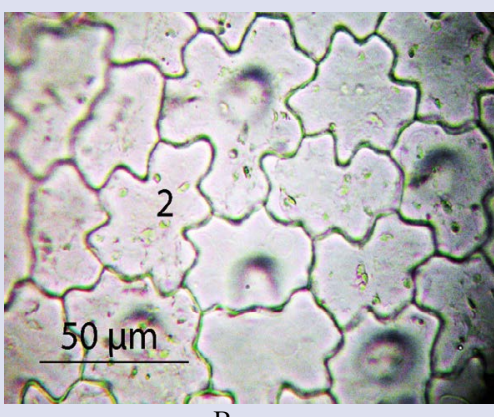

B

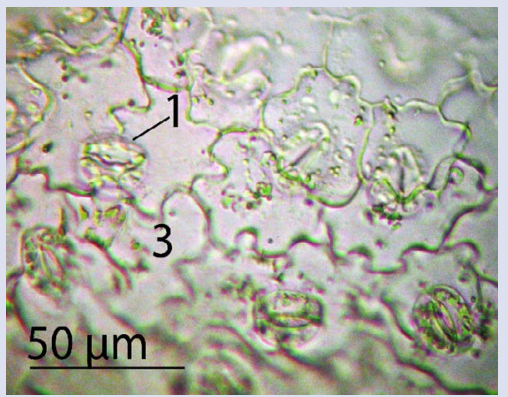

D

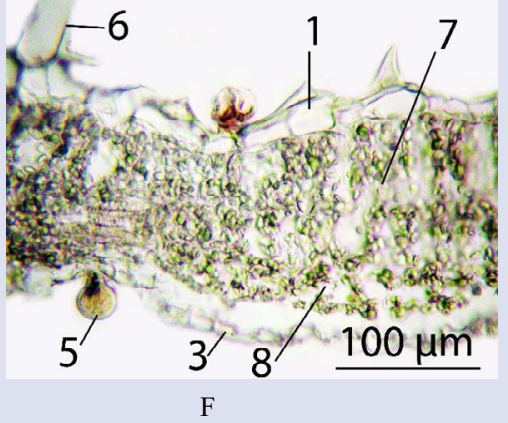

$\mathrm{F}$

Figure 1: Microphotographs of the leaf: A, C, E-Elsholtzia stauntonii, B, D, F-Elsholtzia ciliate, where: 1 stomata, 2 - adaxial epidermis, 3 - abaxial epidermis, 4- great ether-oil glands, 5 -small glandular trichomes, 6 - non-glandular trichomes, 7 - palisade mesophyll, 8 - spongy mesophyll.
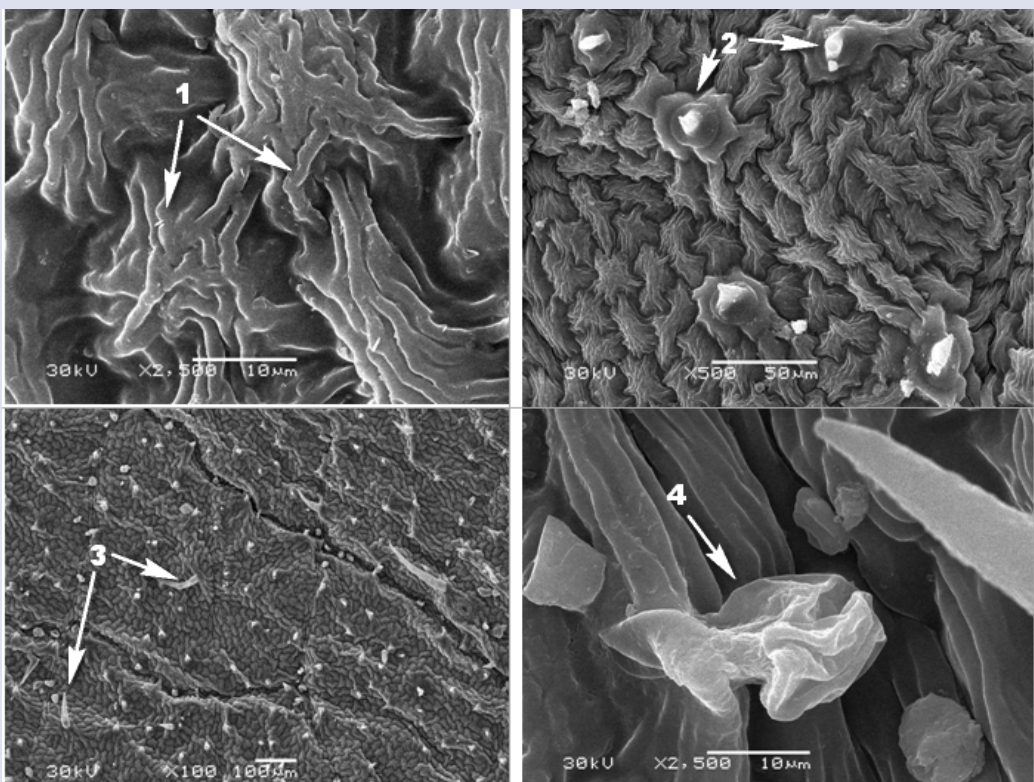

Figure 2: Ultrastructure of the adaxial epidermis of the leaf Elsholtzia stauntonii Benth, where: 1 - cuticle folded type; 2 - hooked papilla; 3 - multicellular tape-shaped trichomes; 4 - small multicellular glands. 


\section{Ultrastructure of E. stauntonii leaves has the following characteristics.}

Leaf is hypostomatic, anomocytic stomata evenly distributed on the lower surface of the leaf blade, slightly above the level of the main epidermal cells. The adaxial surface of the leaf blade of the studied species is collicular. The projections and outlines of epidermal cells are variative. Above the mesophyll there are cells with flattened projections and tortuous outlines, in the area of vascular bundles cells are with elongated projections and tortuous outlines. The cuticle is well developed. Pubescence is of mixed type, formed by hairs (simple and glandular). On the upper surface of the leaf there are three types of trichomes: papillae that is well-developed at the base, multicellular ribbon-shaped trichomes and small glands. Glandular trichomes which placed on the leaf surface are not uniform, most of them are observed in the veins, much less between them. They have a leg, which consists of three cell approximately the same size, and a single-celled head. Simple hairs - bristly, have a warty surface and vary in length. They are observed both on the vein and on the entire surface of the leaf blade.

In the studied species the abaxial surface differs from the adaxial. It is characterized by more pronounced wrinkles of the cuticle. In addition, the central vein of the leaf is densely pubescent with trichomes: long ribbon-shaped, short spines, papillae and glands. On the entire surface of the leaf blade there are densely placed large glands, which are formed by an eight-cell head and a short three-cell leg.

Ultrastructure characteristic of the leaf of Elsholtzia ciliata Thunb. are similar to the previous species.

The leaf as in the previous species is hypostomic, anomocytic stomata evenly distributed on the lower surface of the leaf blade, slightly above the level of the main epidermal cells. Adaxial surface of the leaf blade of the studied species in contrast to the previous is spinous-comb. The boundaries of the cells are clear. The projections and outlines of epidermal cells are variative. Above the mesophyll there are cells with flattened projections and tortuous outlines, in the area of vascular bundles cells have elongated projections and tortuous outlines. The cuticle is well developed. Pubescence of mixed type is formed by simple and glandular hairs. On the upper surface of the leaf there are three types of trichomes: papillae, multicellular tape-shaped trichomes (very rare) and small glands. Pubescence is observed mainly along the veins. The structure of trichomes does not differ from those of the previous species.

In the studied species the abaxial surface differs from the adaxial. It is characterized by the presence of large glands, which are formed by an eight-cell head and a short three-cell stalk, and are located throughout the abaxial surface of the leaf. In addition, the central vein of the leaf is pubescent with trichomes: long ribbon-shaped, short spines, papillae and glands. It should be noted that the central vein of the leaf and the lateral veins of Elsholtzia ciliata have sparse pubescence, in contrast to those of Elsholtzia stauntonii.

Petiole of studied species has a rounded shape on adaxial side (Figure 6 $\mathrm{A}, \mathrm{D})$ and concave with small appendages on the edges of abaxial side (Figure $6 \mathrm{~B}, \mathrm{C}$ ). E. ciliate petiole is twice larger than that of another species, due to a greater leaf blade (Tab. 1). On both sides it is covered with simple multicellular trichomes, much biger on abaxial side. Length of such E.ciliate trichomes is three times biger compared to the other investigated species (Figure $6 \mathrm{E}, \mathrm{F}$ ). There are small glandular trichomes on both sides of $E$. stauntonii petiole. They occur singly in $E$. ciliate (Figure $6 \mathrm{~F}$ ). The petiole is covered with single-layer epidermis, with while adaxial epidermis has twice thicker outer cell wall. There are 4-5 layers of angular collenchyma are placed beneath epidermis (Figure 6). Vascular system is represented as a crescent-placed collateral bundle (Figure 6).

The petals of the studied species covered by abaxial simple glandular trichomes (Figure $6 \mathrm{G}, \mathrm{H}$ ). At petals E. stauntonii can see only long trichomes (Figure 1), while E. ciliate long trichomes are just on the edge of the petals.

The study of the ultrastructure of the calyx and flower petals of both species showed species characteristics. The calyx of the Elsholtzia stauntonii is pubescent, mixed, formed, as well as pubescence with trichomes of several types: long ribbons, spines, papillae.

In the petals of this species the basal part has a dense pubescence, which is formed by long trichomes, in addition, there are large glands, the structure of which is described above. In the distal part of the petals
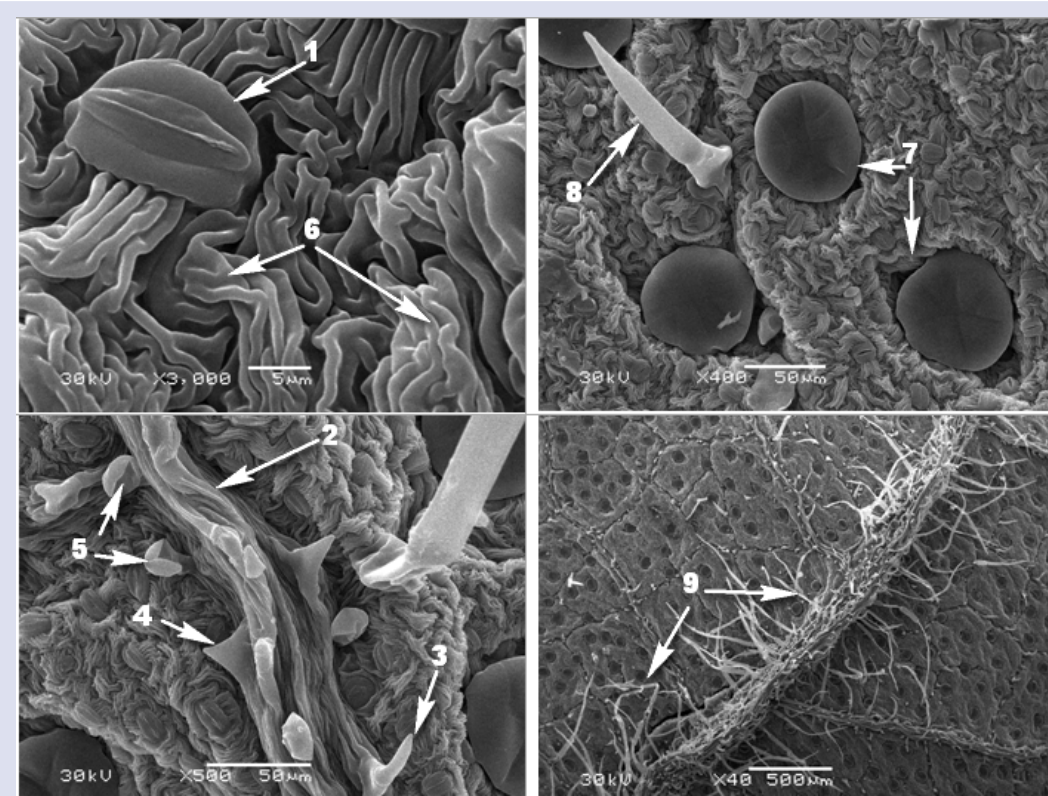

Figure 3: Ultrastructure of the abaxial epidermis of the leaf blade Elsholtzia stauntoni Benth, where: 1 - stomata; 2 - central vein; 3 - short spines; 4- hooked papilla; 5 - small multicellular glands; 6 - basic epidermal cells; 7 - large multicellular glands; 8 -ultrasculpture of tape-shaped trichoma; 9 - multicellular tape-shaped trichomes. 


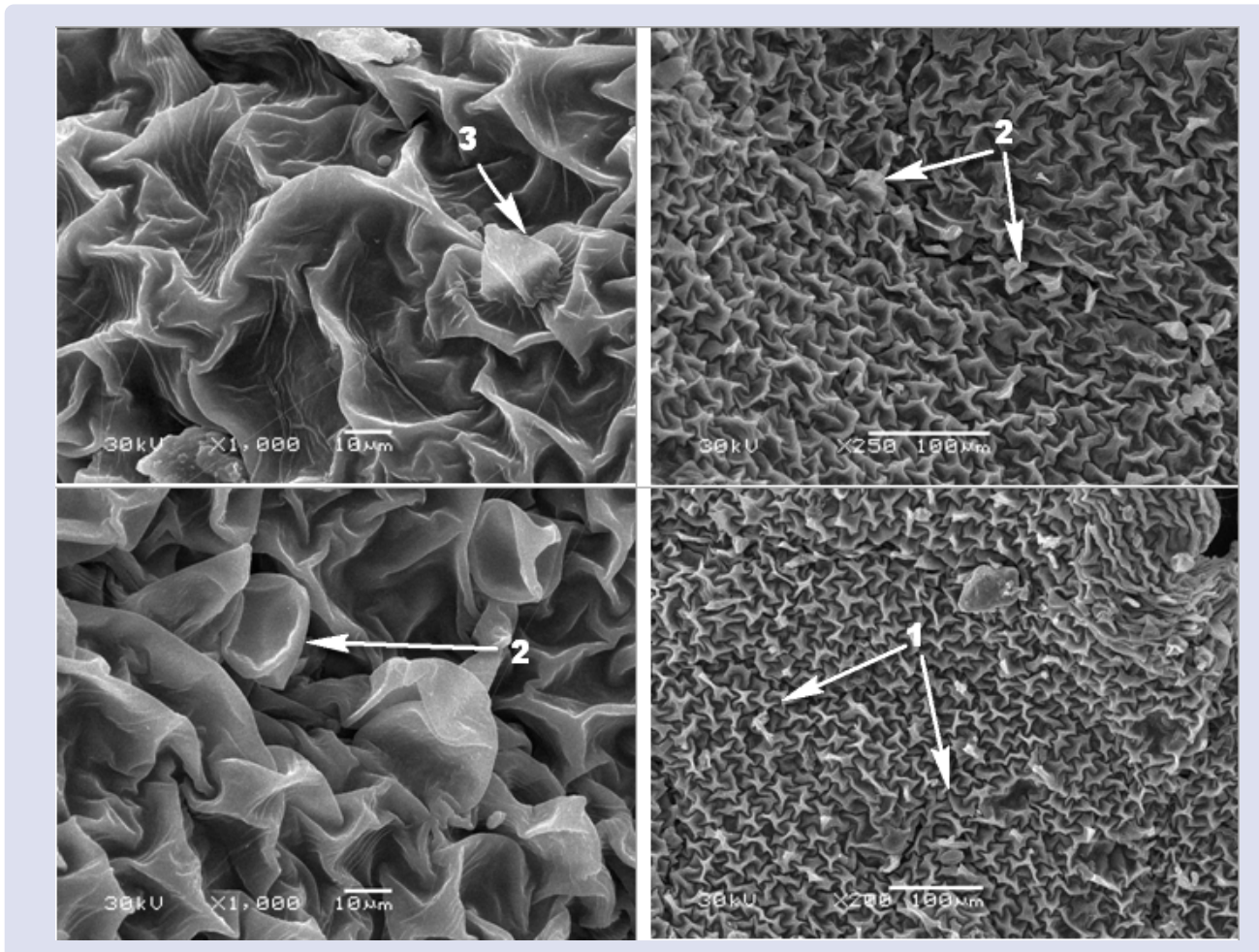

Figure 4: Ultrastructure of the adaxial epidermis of the leaf blade Elsholtzia ciliata, where: 1 - basic epidermal cells; 2 - unicellular spines; 3 - papillae.

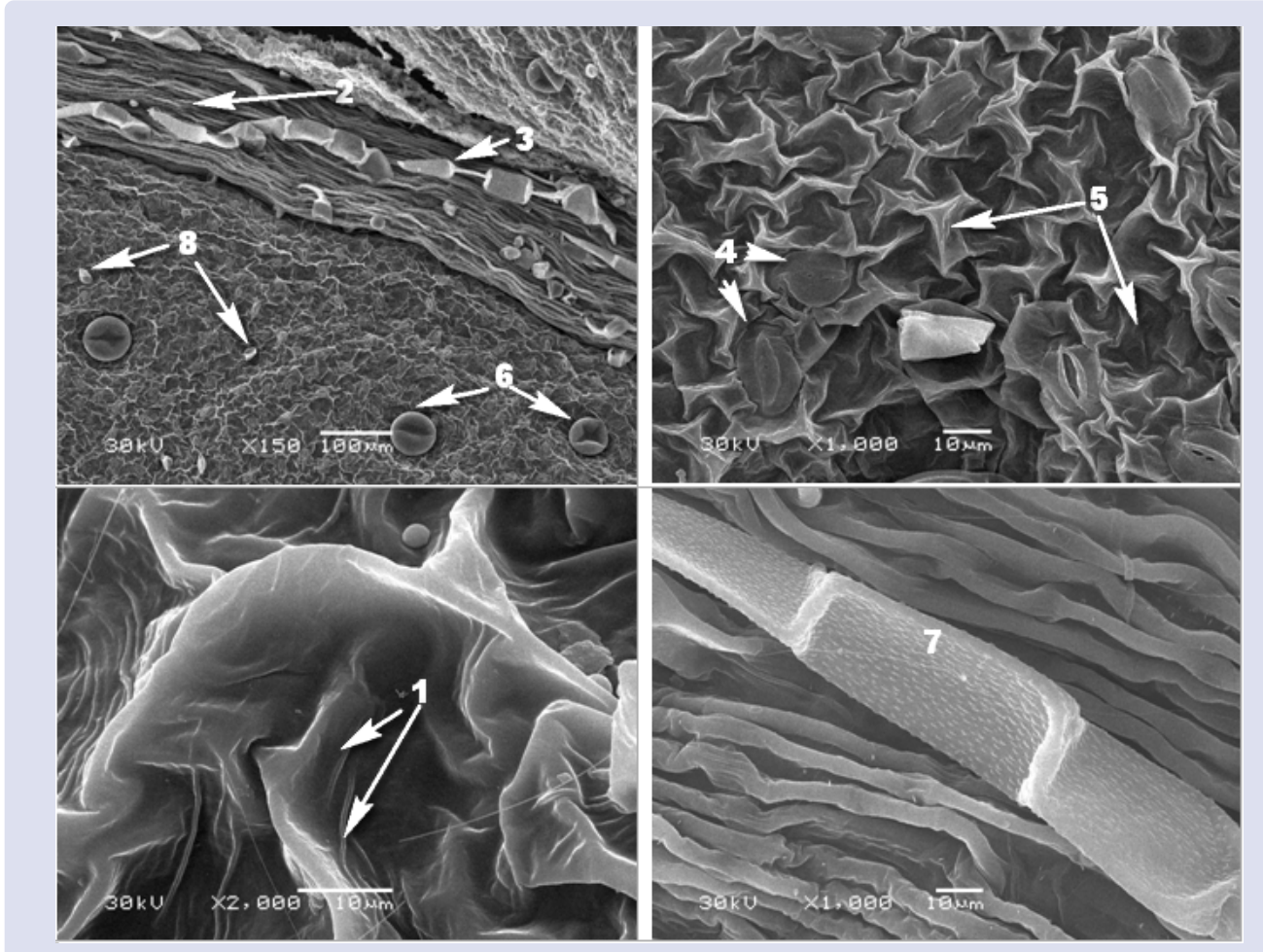

Figure 5: Ultrastructure of the abaxial epidermis of the leaf blade Elsholtzia ciliata, where: 1 - cuticle of smooth type; 2 - central vein; 3 - multicellular tape-shaped trichomes; 4 - leaf stomata; 5 basic epidermal cells; 6 - large multicellular glands; 7 - ultrasculpture of tape-shaped trichoma; 8 - small multicellular glands. 


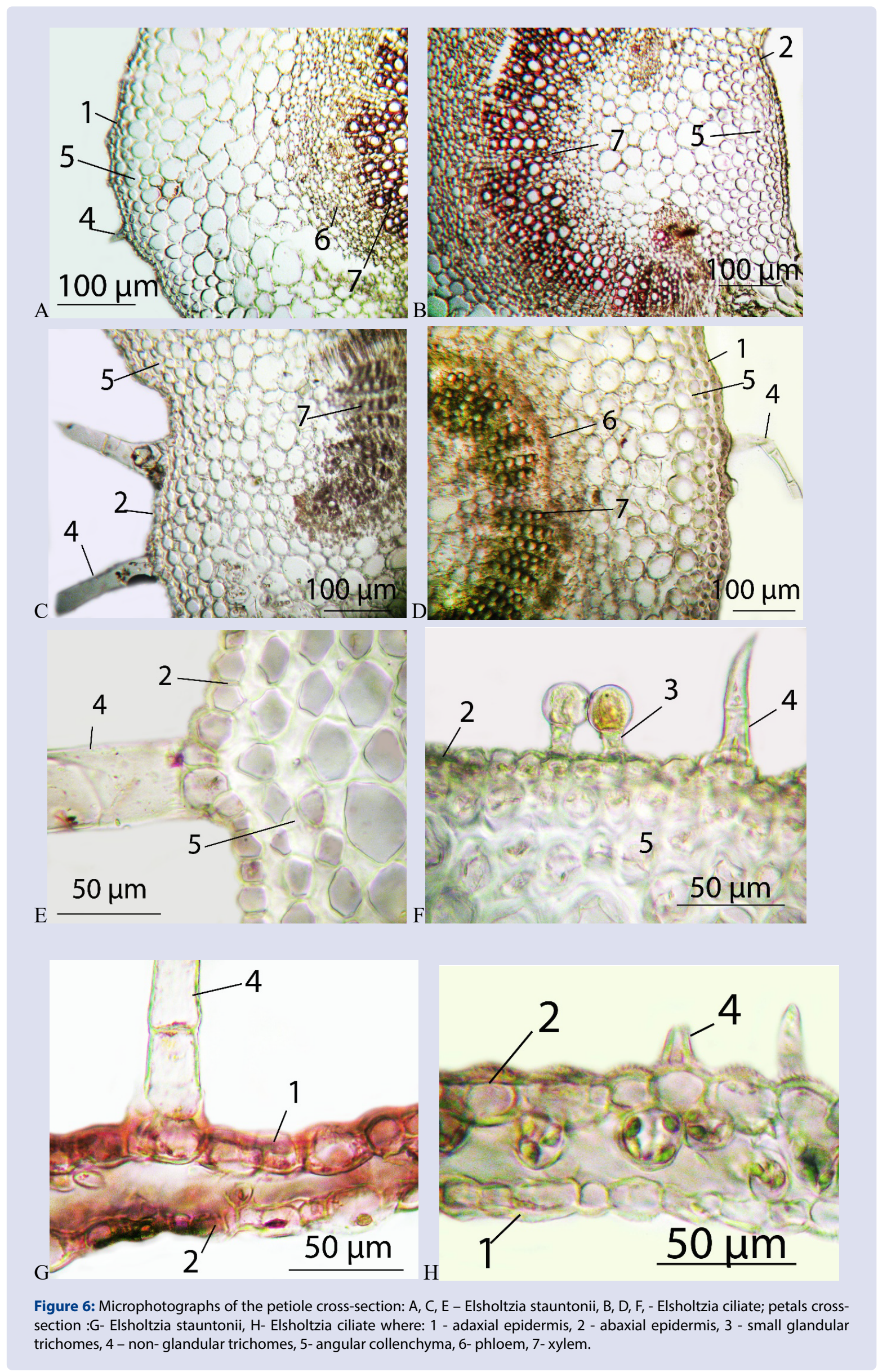




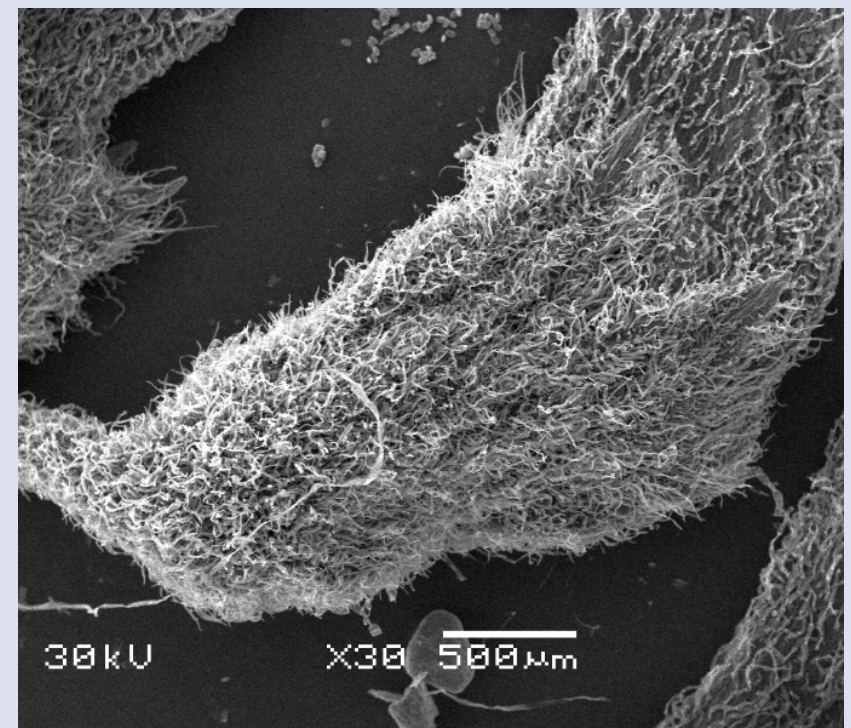

Figure 7: The calyx of the flower of Elsholtzia stauntonii Benth.

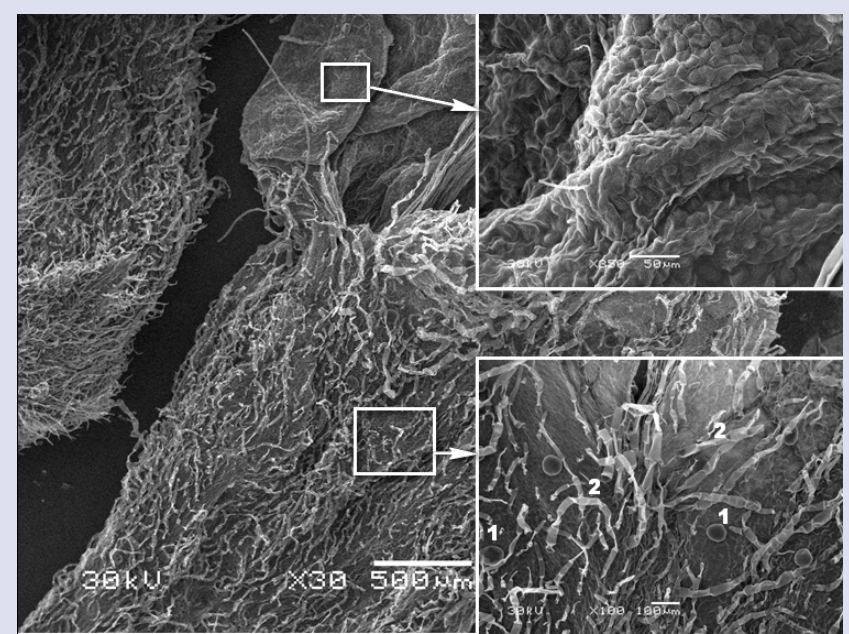

Figure 8: Ultrastructure of the epidermis of flower petals Elsholtzia stauntonii Benth, where: 1 - large multicellular glands; 2- ribbon-shaped long trichomes.
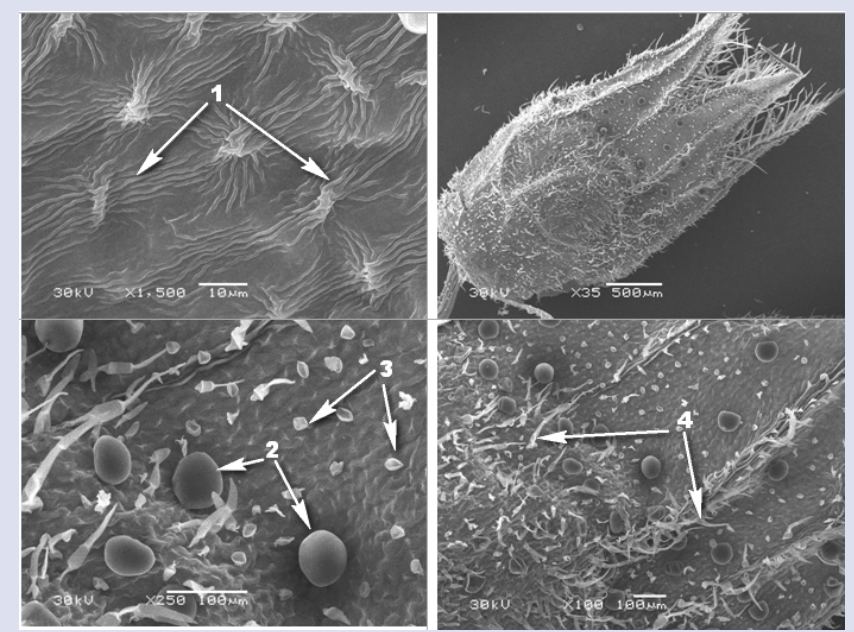

Figure 9: Ultrastructure of the epidermis of the petals and calyx of the flower Elsholtzia ciliate:

1 - cuticle; 2 - large multicellular glands; 3 - small multicellular glands; 4 - ribbon-shaped long trichomes.

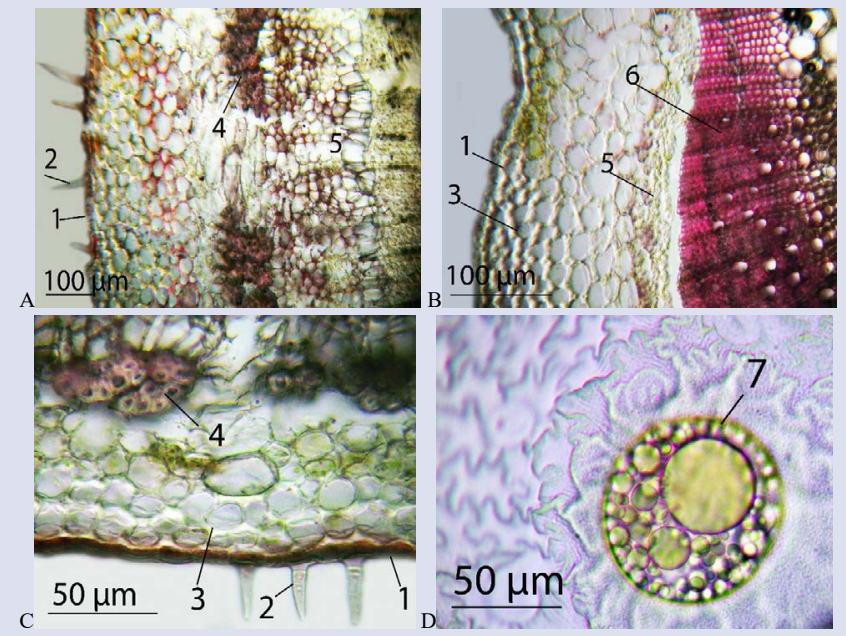

Figure 10: Microphotographs of stems: A, C - E. stauntonii, B - E. ciliate; and $D$ - large ether-oil glands on the leaf surface E. stauntonii; where: 1epidermis, 2 - non glandular trichomes, 3 -collenchyma, 4-sclerenchyma, 5-phloem, 6-xylem, 7- great ether-oil glands on the leaf surface.
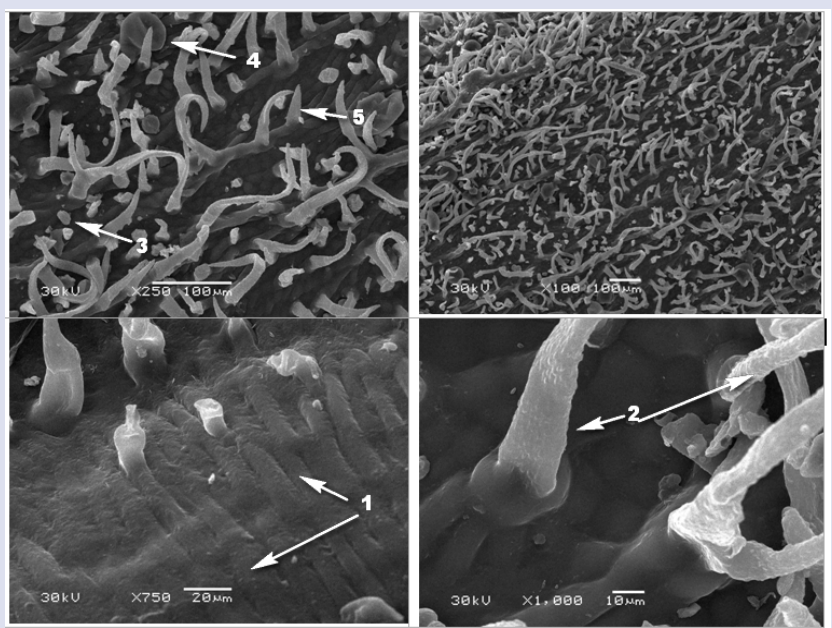

Figure 11: Ultrastructure of the stem surface of Elsholtzia stauntoni Benth., where: 1 - basic epidermal cells; 2 - long tape-shaped trichomes; 3 - small multicellular glands; 4 - large multicellular glands; 5 - thorns.

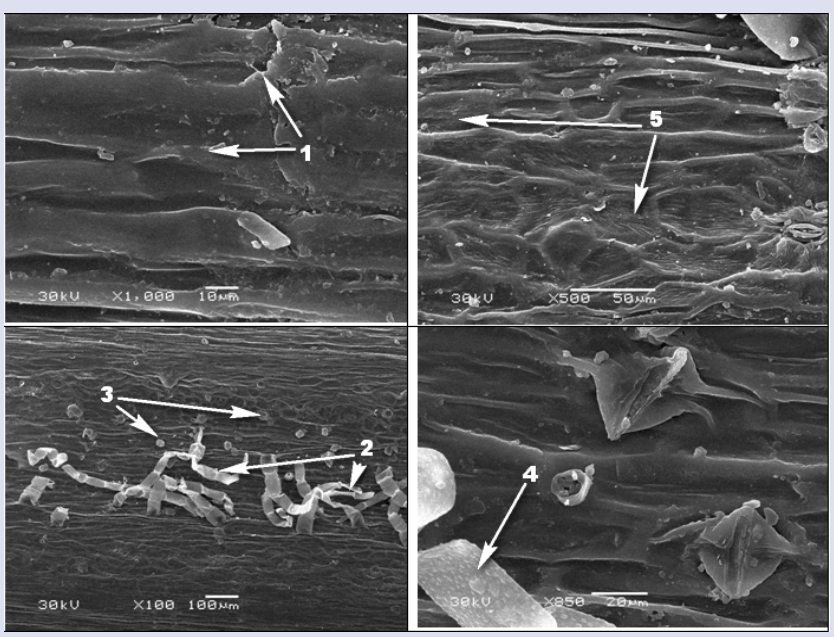

Figure 12: Ultrastructure of the stem surface of Elsholtzia ciliata, where: 1- wax crusts; 2 - multicellular tape-shaped trichomes; 3 - small glands; 4 - ultrasculpture tape-shaped trichomes; 5 - basic epidermal cells. 

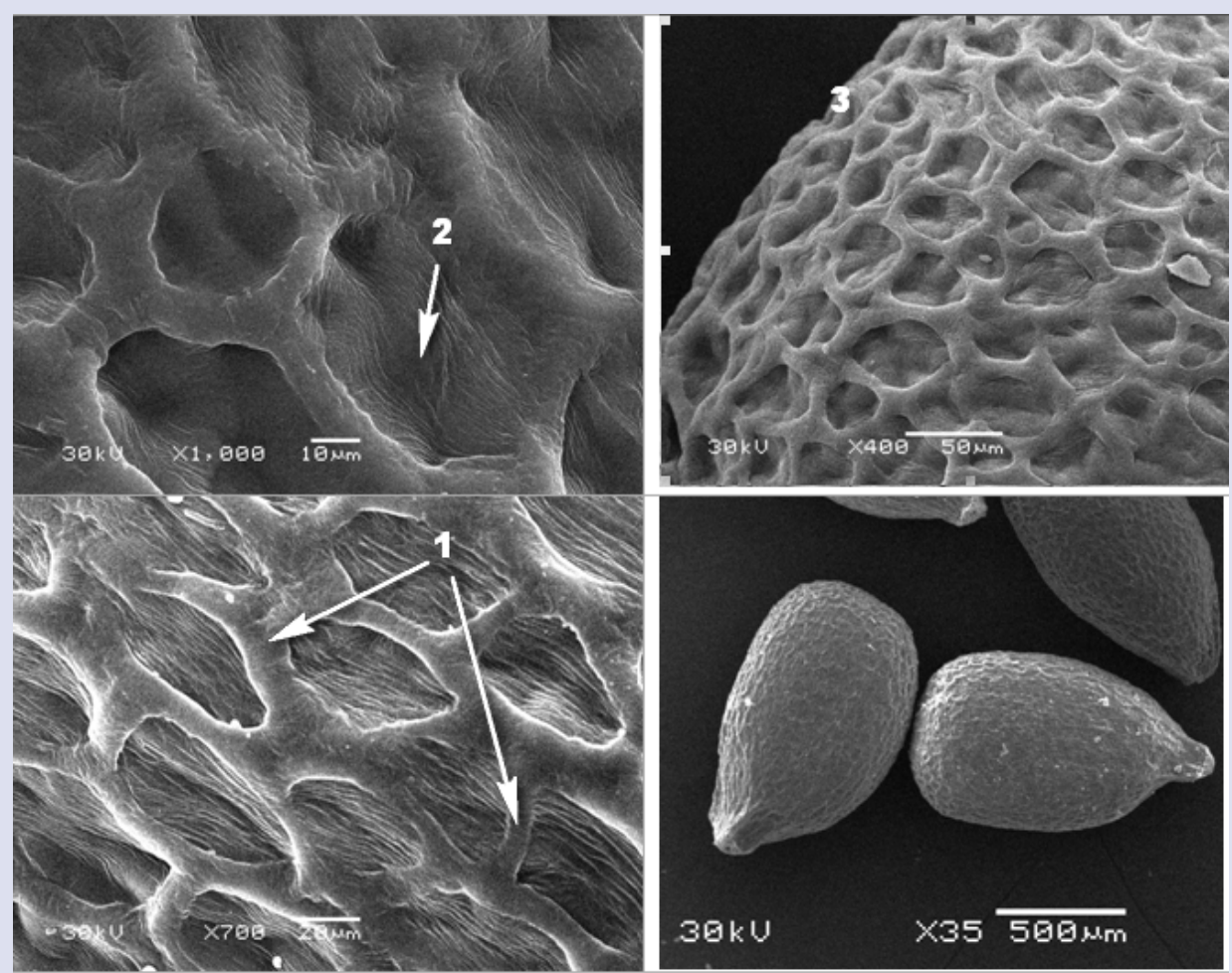

Figure 13: Ultrastructure of the seed surface of Elsholtzia stauntonii, where: 1 - anticline epidermal walls; 2 - periclinal epidermal walls; 3 - mesh ultrastructure of the seed surface.

pubescence is almost absent, sometimes there are single trichomes. The relief of the surface of the epidermis is pitted, periclinal walls are slightly concave, are located below the level of anticlinal walls.

The calyx of the E. ciliate has sepals dense, mixed, formed, as well as pubescence by trichomes of several types. In particular, long tapeworms, spines, papillae and glandular trichomes of two types: large glands with a multicellular head and small glands with a unicellular head. The largest number of large glands is observed in the upper part of the sepals (in the area of the teeth of the calyx), and vice versa in the basal (grown) part of the calyx there is more ribbon-like trichomes, and less glandular.

The petals have a slight pubescence (solitary trichomes), in contrast to the previous species. In the distal part of the petals there is no pubescence, sometimes there are single trichomes, but almost every epidermal cell carries papillae formed by the outer periclinal wall and folds of the cuticle. The relief of the surface of the epidermis is spongy, the periclinal walls are slightly convex, the cuticle forms folds.

The stems of both species are covered with single-layer epidermis, with the epidermis and the outer cell wall of epidermal cells in E. ciliate are significantly thicker than those in another species (Figure 10B, Tab. 1). E. stauntonii has relatively thin epidermis with a dense cover with trichomes (Figure 10A), with numerous not glandular trichomes and small single celled glandular trichomes on the leg. In the stem of $E$. stauntonii 4-5 layers of collenchyma evenly placed under the epidermis, while in E. ciliate cluster of collenchyma alternates with lots chlorenchyma, forming a rectangular shape of the stem (Figure $10 \mathrm{~B}$ ). The primary phloem in E. stauntonii forms a massive sclerenchymal cap (Fig. $10 \mathrm{~A}, \mathrm{~B}$ ), and another species scleretizes only a few elements of the primary phloem Xylem is well developed in both species.

Ultrastructure of the stem of Elsholtzia stauntonii Benth. has the following characteristics.
The surface of the stem is collicular. The boundaries of the cells are clear. Periclinal walls of epidermal cells are convex. Distal and proximal anticline walls do not differ in thickness. Epidermal cells are characterized by flattened or elongated projections and tortuous outlines. The cuticle is well developed, there is epicuticular wax in the form of pellicles. There is a dense complex pubescence, formed by trichomes of several types: small glands, large glands, spines, long hairs. All trichomes, except thorns, are multicellular. The small glands have a unicellular head and a three-celled stalk; large glands are formed from a large octagonal head, and a short leg, which is composed of three tangentially elongated cells. Simple hairs have a warty surface and vary in length, from small to several times larger.

Ultrastructure characteristic of the stem of Elsholtzia ciliata are differ from the previous species. The surface relief of the stem, in contrast to the previous species, varies within one plant: between the ribs the surface relief is reticulate (anticlinal walls of epidermal cells are thickened, periclinal walls are almost flat), along the ribs - pitted (distal and proximal periclinal walls - significantly thickened, concave). The boundaries of the cells are clear. Epidermal cells are characterized by flattened (between the ribs) or elongated (along the ribs) projections and tortuous outlines. The cuticle is well developed, in contrast to the previous species there is epicuticular wax in the form of crusts. In addition, E. ciliata differs from $E$. stauntonii in the degree of pubescence. In contrast to the previous species, $E$. ciliata has a slight pubescence formed by long ribbon-shaped trichomes, small glands. The structure of trichomes does not differ from those of the previous species. In this species, in contrast to the previous one, there are no large glands on the stem formed from a large octagonal head and a short stalk, which is composed of three tangentially elongated cells.

E. stauntonii seeds had not been studied because the plant blooms in late September-early October and in the climate of Ukraine the seeds do not have time to ripen. The plant is propagated by cuttings. 
Seeds of $E$. ciliata are oblong-ovate, with a markedly narrowed chalazal end, which forms an appendage in the form of a "nose" and a rounded micropilar end. They have round scar. Seed stalk is not expressive. Relief (general appearance of the seed coat (tests)) is reticulate. The shape of spermoderm cells is angular, polygonal, but the cells are mostly isodiametric.

\section{CONCLUSION}

Thus, as a result of a study of representatives of two species of the genus Elsholtzia - Elsholtzia ciliata and Elsholtzia stauntonii - we found that the species are characterized by both common and distinctive features.

The studied species are characterized by hypostomatic leaf, anomocytic stomata evenly distributed on the lower surface of the leaf, slightly above the level of the main epidermal cells, flattened projections and tortuous outlines of cells, well-developed cuticle, the same structure and type of trichomes. Along with these there are qualitative features that clearly distinguish one species from another.

For example, the distinguishing feature on the anatomical level E. ciliate from $E$. stauntonii is the presence of small glandular trichomes, singly placed on the veins and the presence of long non glandular trichomes on the central vein of the abaxial side. Non glandular trichomes $E$. ciliate are three times longer compared to other investigated species. The presence of numerous trichomes and massive clusters of stem sclerenchyma in E. stauntonii can be considered additional taxonomic criteria for comparing the studied species. Additional taxonomic characteristics can serve as morphometric traits that are true difference.

The central vein of a leaf and the lateral veins of $E$. ciliata have sparse pubescence, in contrast to those of $E$. stauntonii, which are strongly pubescent. The abaxial surface of the leaf blade of $E$. stauntonii is characterized by more pronounced wrinkling compared to that of $E$. ciliata. According to the degree of pubescence of the stem and the surface relief of the epidermis, the studied species also clearly differ: E. ciliata is characterized by reticular or pitted surface relief and sparse pubescence formed by long ribbon-shaped trichomes, small glands, and localized mainly between the ribs; E. stauntonii - collicular relief of the stem surface and dense uniform pubescence with different types of trichomes.

The practical significance of our research will use to work out the project and quality control methods for medicinal herbal raw material - «Herba Elsholtziae Stauntonii», «Herba Elsholtziae ciliate».

\section{CONFLICTS OF INTEREST}

None.

\section{REFERENCES}

1. Yun-Chang Jeon, Tae-Soo Jang, Suk-Pyo Hong. Nutlet morphology in the tribe Elsholtzieae (Lamiaceae). Nordic Journal of Botany. 2020; Vol.38, Issue 8: 1-11.

2. Liu, A.L., Lee, S.M.Y., Wang, Y.T., Du, G.H. 2007. Elsholtzia: review of traditional uses, chemistry and pharmacology // Journal of Chinese Pharmaceutical Sciences. - 16: pp. 73-78.

3. Guo, Z., Liu, Z., Wang, X. et al. 2012. Elsholtzia: phytochemistry and biological activites // Chemistry Central Journal. - 6 (147): pp. 1-8. DOI: 10.1186/1752153X-6-147.

4. Sokolov P.D. (editor-in-chief). Plant resources of the USSR: Flowering plants their chemical composition and use; Families Hippuridaceae-Lobeliaceae. SPb Science, 1991: 24-25.

5. Li, P. et al. Molecular phylogenetics and biogeography of the mint tribe Ehlsholtzieae (Nepetoideae, Lamiaceae), with an emphasis on its diversification in East Asia. 2017; Sci. Rep. 7: 2057.

6. Guo Z., Liu Z., Wang X., et al. Elsholtzia phytochemistry and biological activities Chemistry Central Journal . 2012; № 6. 147.

7. Ai-Lin Liu, Simon M.Y. Lee, Yi-Tao Wang and Guan-Hua Du. Elsholtzia: review of traditional uses, chemistry and pharmacology. Journal of Chinese Pharmaceutical Sciences. 2007; Vol. 16: 73-78.

8. Liu X., Jia J., Yang L., et al. Evaluation of antioxidant activities of aqueous extracts and fractionation of different parts of Elsholtzia ciliate. Molecules. 2012; № 17: 5430-5441

9. Pudziuvelytea L., Stankeviciusb M., Maruskab A., Petrikaitede V., et al. Chemical composition and anticancer activity of Elsholtzia ciliata essential oils and extracts prepared by different methods. Industrial Crops \& Products.2017 Vol. 107:90-96.

10. Thiers, B. [continuously updated]. Index Herbariorum: a global directory of public herbaria and associated staff. - Botanical Garden's Virtual Herbarium, New York, http://sweetgum.nybg.org/science/ih/ [accessed 15 Feb 2020]

11. Dobrochayeva D. N., Kotov M. I., Prokurin Yu. N. The determinant of higher plants of Ukraine. 2nd ed. ,Kiev: Phytosotsiocentre, 1999; P. 213-214.

12. Pausheva Z.P. Workshop on plant cytology. Moscow: Agropromizdat, 1988; 271 p

13. Romeys B. Microscopic machines. - Moscow:"Foreign Literature", 1954.718 p

14. Zaharevich S.F. To describe the methodology sheet. Bulletin of Leningrad University, 1954; № 4: 65-75.

15. Baranova M.A. Classification of morphological types of stomata . Botanical Journal, L., 1985; Vol. 70, №12:1585-1595.

16. Furst G.P. Methods of anatomical and histochemical research of plant tissues Moscow: Nauka, 1979; $154 \mathrm{p}$. 


\section{GRAPHICAL ABSTRACT}
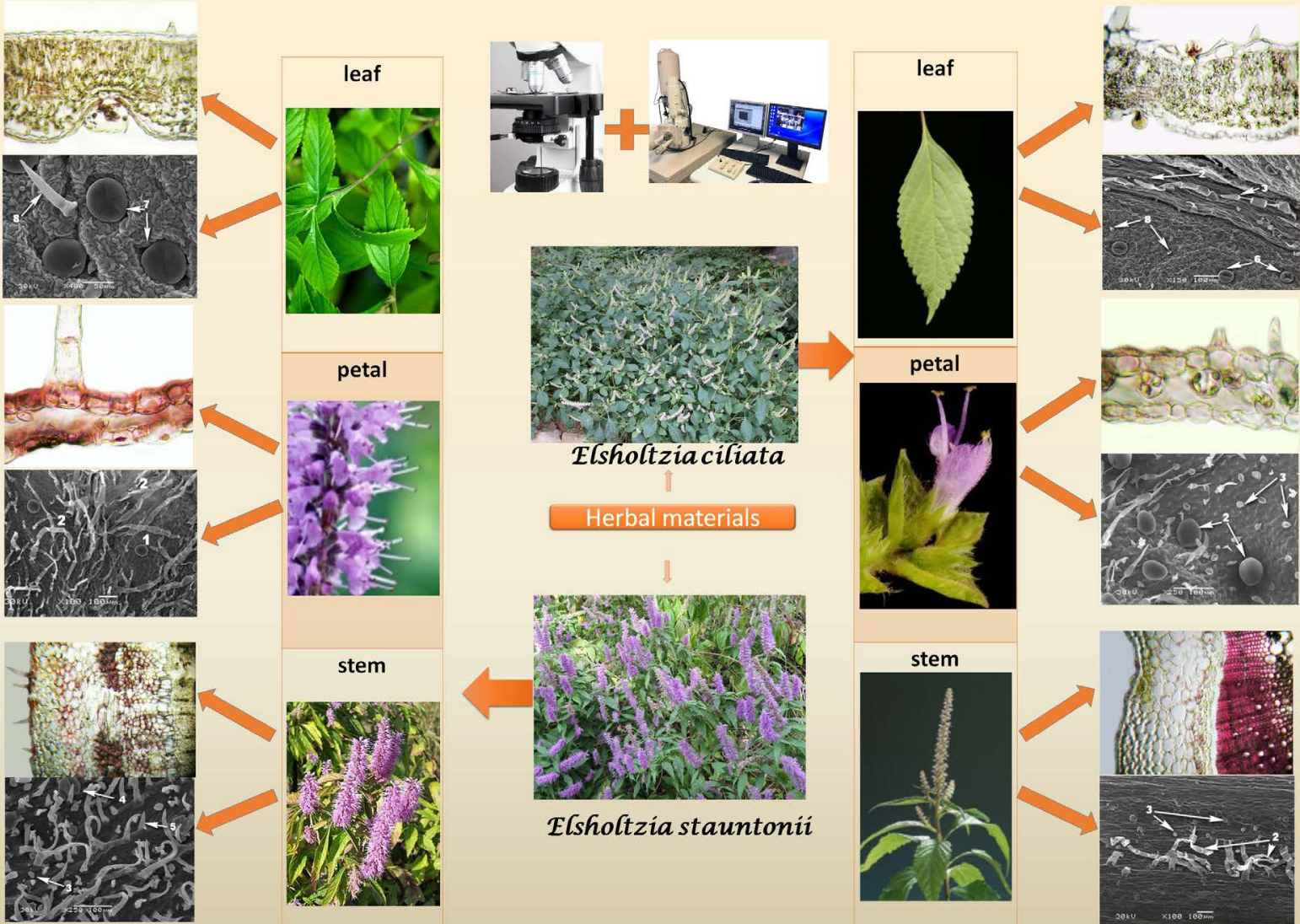

Elsholtziaciliata
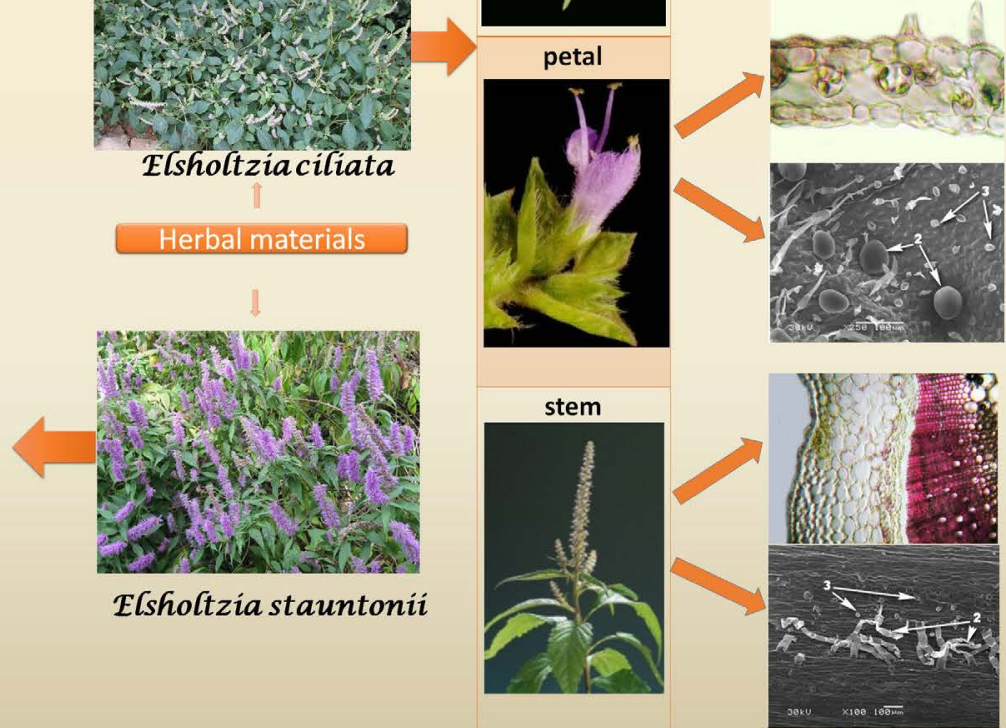

\section{ABOUT AUTHORS}

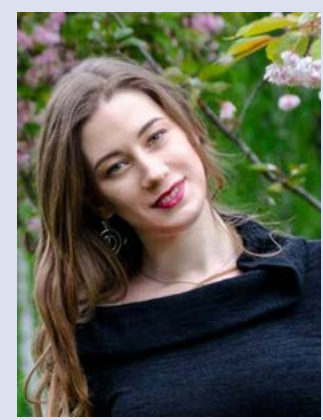

\section{Liudmyla Zotsenko}

Liudmyla Zotsenko has been working as a junior researcher and chromatographer in State Laboratory of Quality Control of Drugs in State Institution "Institute of Pharmacology and Toxicology National Academy of Medical Sciences of Ukraine", Kyiv (Ukraine) since 2013. Since 2018 she is a graduate student at the Chemistry of Natural Compounds department in National University of Pharmacy. Her research areas of interest are natural products and herbal drug technology, that also extends into identifying, characterization of phytocostituents from the medicinal plants.

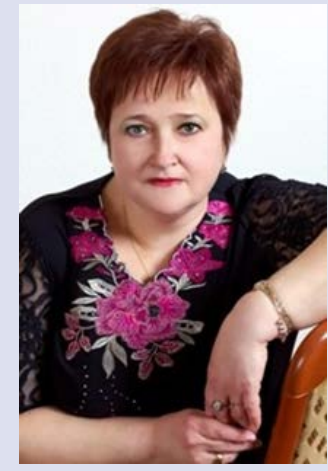

\section{Kislychenko Victoria}

Kislychenko Victoria has received her Ph.D. in Pharmaceutical Sciences in 1985. Since 1992 worked as Associate Professor of Pharmacognosy department at Kharkiv Pharmaceutical Institute. She resieved doctoral degree in 1999, dissertation on the topic "Pharmacognostic study of family members Agrus, Bruslinna, Rannikov and development of drugs based on them". In 2002 she was awarded the academic title of professor. Since 2004 - Head of the Department of Chemistry of Natural Compounds of National University of Pharmacy, Kharkiv (Ukraine). She has developed 21 drugs that are produced by the pharmaceutical industry. 

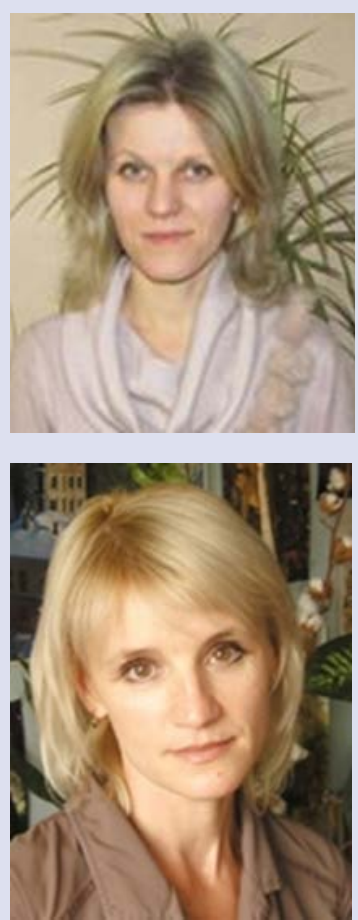

\section{Nataliia Nuzhyna}

Nataliia Nuzhyna has received her Ph.D. in Biology (Specialty: Cytology, cell biology, histology ) in 2004. She has been working at the Taras Shevchenko National University of Kyiv, Kyiv (Ukraine) since 2004; since 2018 - as a senior researcher of Institute Biology and Medicine of Taras Shevchenko National University of Kyiv.

Current Research: Ecological, anatomical, morphological, physiological, cytogenetic and biochemical investigations of plants for: studying of adaptation process to unfavorable conditions plants from different ecological groups; solution of different taxonomical questions; effective methods of ex situ and in situ plant conservation. Editorial board member: Henry Journal of Cytology \& Histology. Author of over 100 scientific publications.

\section{Okasana Futorna}

Okasana Futorna has graduated from the Faculty of Chemistry and Biology, Nizhyn State Pedagogical University. Nikolai Gogol, qualification - teacher of biology and chemistry in 1995. She has received her Ph.D. in Biological Sciences in 2008. Currently work as senior scientist at Phytohormonology department in the Mikola Grigorovich Kholodny Institute of Botany, Kyiv (Ukraine).

Cite this article: Zotsenko L, Nuzhyna N, Kyslychenko V, Futorna O. Anatomical and Ultrastructure Differences Between Some Species of the Genus Elsholtzia Willd. of Flora of Ukraine. Pharmacogn J. 2021;13(4): 977-987. 